\title{
Leitura de Textos Ficcionais e a Abordagem Escolar de Literatura: contribuicões para uma Pedagogia da Escolha
}

Rogério de Almeida', Marcos Ferreira Santos², Júlia Campiolo Porto ${ }^{3}$

Recibido: 02-02-2016

Aceptado: 15-04-2016

\begin{abstract}
RESUMO
Este artigo busca contribuir para as discussões acerca da Pedagogia da Escolha colocando em pauta a circulação social da literatura na contemporaneidade e a escolarização do texto literário. Partindo da premissa de que não há espaço para maniqueísmos e discursos totalizantes no cenário sociocultural atual, critica-se o modo como a cultura escolar impõe discursos classificatórios para o ensino de literatura. Nesse cenário, a internet se constitui como uma potencial auxiliar na formação de leitores dada a quantidade de conteúdos literários que circulam por meio dela. A hipótese de trabalho é que o conhecimento e uso consciente das potencialidades da internet promove a individualização da trajetória educativa da pessoa e a aposta na capacidade de autogestão de sua formação.
\end{abstract}

Palavras-chave: Pedagogia da Escolha; itinerário de formação; ensino de literatura; contemporaneidade.

1. Professor Associado da Faculdade de Educação da Universidade de São Paulo (FEUSP). Professor visitante da Universidad Santo Tomás (Colômbia). Lidera o GEIFEC (Grupo de Estudos sobre ltinerários de Formação em Educação e Cultura) e coordena o Lab_Arte (Laboratório Experimental de Arte-Educação \& Cultura) com Marcos Ferreira Santos. É Editor Colaborador para a área de Educação da Revista Machado de Assis em Linha. Bacharel em Letras (1997), Doutor em Educação (2005) e Livre-Docente em Cultura e Educação, todos os títulos pela Universidade de São Paulo (USP). Trabalha com temas ligados a Cinema Literatura, Filosofia Trágica e Imaginário. Site: www.rogerioa.com.

Correo: rogerioa@usp.br

2. Folklorista, arte-educador e pedagogo, Doutor (FE-USP, 1998) e pós-doutoramento em Hermenêutica Simbólica pela Universidad de Deusto (Bilbao, País Basco, 2003). Atualmente é professor de MITOLOGIA, livre-docente na FE-USP. Professor visitante de "mitohermenêutica" nas Universidad de Deusto, Bilbao (E.H. País Basco, 2003), Universidad Complutense de Madrid (2005), Universidad Autónoma de Madrid (2009 e 2010), Universität Ramón Llull (Barcelona, 2005), Universidad San Buenaventura Cali (Colombia, 2009 e 2010), Universidad de Concepción (Chile, 2011), IAEN - Instituto de Altos Estudios Nacionales da Universidad de Postgrado del Gobierno (Ecuador, 2010 a 2012), Cátedra Agustin Nieto Caballero (Colombia, 2012), Universidad Santo Tomas (Colombia, 2013) e Planetario de Bogotá (2013). Coordenador do Lab_Arte com Rogério de Almeida. Tem atuação em pesquisa, ensino e extensão na área de Antropologia da Educação, sobretudo nos seguintes temas: mitologia comparada, ambientalismo, antropologia do imaginário, mitohermenêutica, religiosidade, terceira-idade e arte-educação.

Correo: marcosfe@usp.br

3. Mestre em Educação pela Faculdade de Educação da Universidade de São Paulo e Graduada em Letras (Português/Italiano) pela Faculdade de Filosofia, Letras e Ciências Humanas da mesma Universidade. $\mathrm{Na}$ Iniciação Científica se dedicou a pesquisar o papel do imaginário no processo de recepção de textos literários inserido no diálogo entre "literatura de entretenimento" e cânone escolar. A monografia, "Literatura e Educação: Análise Simbólica da Saga Crepúsculo", foi contemplada com a publicação na série IC/FEUSP 2011 . No mestrado estudou o diálogo entre a leitura de ficção e a escolarização do texto literário inseridos na paisagem contemporânea de mudanças paradigmáticas no acesso à informação e bens culturais. Correo: julia.porto@usp.br 


\title{
Reading fiction texts and the scholarly approach to Literature: contributions to a Pedagogy of choice
}

\begin{abstract}
This paper contributes to the discussions regarding the Pedagogy of choice, by questioning the social circulation of Literature in contemporaneity and the schooling of the literary text. Assuming that there is no room for Manichaeism and totalizing discourses in the current sociocultural setting, the way in which scholarly culture imposes classificatory discourses on the teaching of Literature is criticized. In this scenario, the Internet is a potential complement in the training of readers, given the amount of literary content that circulates there. The working hypothesis is that knowledge, and conscious use of the potential of the Internet, promotes the individualization of the person's educational trajectory and the focus on the capacity of self-management of their formation.
\end{abstract}

Key words: Pedagogy of choice, training schedule, teaching of literature; Contemporaneity.

\section{Lectura de textos ficcionales y el enfoque escolar de literatura: contribuciones para una Pedagogía de la Elección}

\section{RESUMEN}

Este artículo contribuye a las discusiones sobre la Pedagogía de la Elección, al cuestionar la circulación social de la literatura en la contemporaneidad y la escolarización del texto literario. Suponiendo que no hay lugar para maniqueísmos y discursos totalizadores en el escenario sociocultural actual, se critica el modo como la cultura escolar impone discursos clasificatorios a la enseñanza de la literatura. En este escenario, internet es una complementación potencial, en la formación de lectores, dada la cantidad de contenidos literarios que circulan a través 
de ella. La hipótesis de trabajo es que el conocimiento, y uso consciente de las potencialidades de internet, promueve la individualización de la trayectoria educativa de la persona y el enfoque en la capacidad de autogestión de su formación.

Palabras clave: Pedagogía de la elección, itinerario de formación, enseñanza de literatura; contemporaneidad.

\section{Introdução}

Em um período de mudança de paradigma (Morin, 1999), crise das instituições, de fim das metanarrativas (Lyotard, 1993), era da informação ou outras tantas alcunhas que nossos tempos vêm recebendo, todas ao mesmo tempo verdadeiras e falsas dependendo do par os óculos que se usa, uma coisa é certa: as cartas estão todas na mesa. Vinculam-se ideias como "alternativa", "chance", "oportunidade", "escolha"; exaltase sobremaneira a capacidade de atuação do indivíduo, na chave da hipermodernidade (Lipovetsky, 1989).

Não pretendemos nos apoiar, aqui, em um determinismo melancólico nem mesmo em uma noção de livre-arbítrio esfuziante para compreender a noção de escolha; não podemos ceder à tentação das simplificações ou dos extremos maniqueístas. Há, sim, escolhas, alternativas, que caminham "junto", não em sentido oposto a certa expectativa de futuro que nos é sugerida e, para muitos (mais do que se supõe), imposta. É para este grupo de pessoas que o olhar dos teóricos - e dos dispostos poderia se voltar neste século: para a grande maioria da população que, por motivos diversos, se encontra à margem de tudo que já foi dito sobre o "pós-moderno", a "era da comunicação", o "mundo globalizado".

Fundamental, para este exercício, é desfazer-se de duas concepções imprudentes que residem nas entrelinhas de muito do que se fala sobre o assunto: a primeira é a de que todos compartilham de um mesmo ideal de progresso, concepção europeia/norte-americana de mundo que menospreza e folcloriza modos de viver alheios a ela. A segunda, ainda mais perversa, apresenta um horizonte de futuro que ignora o imenso grupo de pessoas para o qual a ideia de progresso compreende, ainda, o acesso a moradia, água potável, saneamento básico e alimentação. 
Portanto, as discussões sobre progresso não devem prescindir de uma compreensão justa de progresso. Também a noção de escolha não pode, jamais, se eximir da ideia de que, para muitos, não há escolhas a serem feitas; relativizar a meritocracia. Para os futuros e atuais educadores, o olhar abrangente e profundo acerca destas questões é condição sine qua non para a prática docente. O conceito de Pedagogia da Escolha propõe a escolha como eixo central do processo educativo abarcando a ideia de que o ser humano está em constante estado de construção; porém, o otimismo que as possibilidades despertam não nega certo grau de determinismo que envolve nossa existência. $O$ desafio, portanto, seria o de fazer dialogar as duas esferas, as potencialidades de viver diante das condições de vida que nos são dadas:

(...) a existência, que não é uma escolha, impõe uma escolha fundamental: se aprovo ou não minha existência. Se eu a gozo, se eu a aceito como é. Quem não afirma a vida, a idealiza, a moraliza, a submete à lógica do dever ser. Impondolhe condições, adia permanentemente uma realização que, embora efêmera, está ao alcance de todos: a adesão ao instante presente. Essa escolha inicial e constante - e nunca exclusivamente racional - é que possibilita ao homem assumir seu destino, ou seja, a somatória das escolhas que faz com o fortuito da existência. (Ferreira-Santos e Almeida, 2012, p. 154)

\begin{abstract}
A Pedagogia da Escolha, ao assumir a localização no mundo do indivíduo como ponto de partida para seu processo de escolhas, assume também a ideia de itinerário de formação, de trajetória, jornada, percurso, isto é, "apostar na escolha é estreitar esse mundo amplo de possibilidadesoutras para um mundo criado de escolhas-minhas." (Almeida, 2010, p. 62). A partir da dicotomia determinismo/escolha, buscaremos compreender de que modo esta atua no campo do ensino de literatura frente aos modos que os educandos usufruem de textos literários fora do ambiente escolar, com base na premissa da Pedagogia da Escolha de que:
\end{abstract}

A escola não é, como se supõe na visão escolacentrista, o espaço privilegiado da educação, mas apenas mais uma instância de formação entre outras tantas. E a pedagogia da escola, do modo como foi e está instituída social e historicamente, opõe-se à pedagogia da escolha, justamente por abolir de suas práticas a dimensão sensível, criativa, simbólica, imaginária, convivial, 
afetual, estética da vida, dimensão que exige a prática da escolha, a abertura ao erro, à incerteza, à inconclusão, ao acaso, ao fortuito, dados que fazem parte da vida, mas que são ignorados pelas pedagogias oficiais. (Ferreira-Santos e Almeida, 2012, p. 155)

\section{Promessa de vida da literatura no século XXI}

Em meio a um processo de mudança paradigmática globalizante que vem redefinindo a posição, a compreensão e a relação do indivíduo com o mundo através da "tecnologização" das coisas humanas, os debates acerca da importância do contato com a arte - inclusa aqui a literatura na formação e cotidiano dos homens ganham uma justificativa a mais e caráter de urgência.

Ainda que os avanços tecnológicos tenham adentrado as mais simples práticas humanas com a atribuição de aspectos universalizantes e homogeneizadores que parecem enquadrar a humanidade em controles e racionalidade descritos em Admirável Mundo Novo, também nunca antes uma quantidade tão grande de conteúdo esteve disponível para consulta, pesquisa e apreciação individual, incluindo bens artísticos. A digitalização, divulgação e compartilhamento de uma infinidade de acervos garante àqueles que têm acesso aos novos suportes - algo em torno de $32 \%$ da população mundial em 2012 e, potencialmente, $50 \%$ em $2017^{4}$ - a oportunidade de ver, ouvir e ler obras que, sem sua disponibilidade gratuita, não poderiam acessar. Também fazendo uso das novas tecnologias, espaços, iniciativas e eventos culturais e de preservação do patrimônio artístico têm a oportunidade de divulgar suas atividades, garantir "casa cheia" e, principalmente, permanência.

Portanto, ao mesmo tempo em que parte da população parece cada vez mais afastada das Humanas por conta da constante e crescente valorização da tecnologia, percebe-se o movimento de preservação e câmbio de conteúdos da área através do uso das recentes formas de acesso e compartilhamento de informações, ação que parece postergar a temerária possibilidade de robotização da vida humana. As novas tecnologias, portanto, apresentam um caráter duplo: afastam e

4. Projeção feita pela empresa de TI Cisco divulgada em fevereiro de 2013. Os dado e estatísticas completas podem ser acessados através do link http://showmetech.band. vol.com.br/metade-da-populacao-mundial-tera-acesso-a-internet-ate-2017/. 
aproximam os indivíduos, homogeneízam e permitem a manutenção das diferenças, trazem o novo e asseguram permanência ao antigo. Dessa forma, os debates sobre os usos, desusos, funções, ações e poder da arte se tornam cada vez mais complexos, visto que nunca antes um grupo tão grande e heterogêneo teve acesso a tantos bens artísticos e culturais e, portanto, à resistência das coisas humanas.

No caso específico da Literatura, a invenção de e-readers e tablets veio acompanhada da apocalíptica possibilidade do "fim do livro de papel". Através da tela, iniciativas como Project Gutemberg, OpenLibrary e, no Brasil, Domínio Público disponibilizam para download gratuito acervos babélicos de obras literárias e, com poucos cliques, tem-se à disposição a obra completa de Machado de Assis, Fernando Pessoa, William Shakespeare, A Divina Comédia, Dom Quixote, Ulisses. Bibliotecas e sebos permitem a consulta online de seu acervo para que os leitores possam verificar a disponibilidade de determinado título sem sair de casa. Por (ainda) vias ilegais, são compartilhados arquivos com obras não só de ficção, mas de teoria das mais diversas áreas, muitos deles raros ou fora de catálogo. Novos títulos são lançados simultaneamente em papel e em formato eletrônico, dando ao leitor a oportunidade de escolher aquele que lhe agrada mais. Existe uma rede social - Skoob - exclusiva para a troca de informações sobre livros e muitos escritores se comunicam com seus leitores através de seus sites, blogs, Facebook e Twitter.

Ao mesmo tempo, megastores de livros de papel são cada vez mais comuns, best-sellers têm números de impressão e vendagem impressionantes, ainda que a qualidade dessas publicações esteja sempre sob suspeita, multiplicaram eventos e feiras literárias no calendário internacional, edições especiais e comemorativas de clássicos da literatura surgem diariamente, assim como versões pocket a preços populares, o que parece contrariar as expectativas mais pessimistas do fim dos livros impressos. A "morte do livro de papel" não é uma alternativa a ser de todo desconsiderada, porém e por enquanto, as novas tecnologias têm cooperado consideravelmente para sua permanência, inclusive incrementando sua divulgação. Segundo dados divulgados recentemente pela Fundação Instituto de Pesquisas Econômicas, em números gerais, a venda de livros diminuiu de 2011 para 2012, porém, houve um aumento no consumo de livros de ficção e não ficção:

O número de exemplares vendidos caiu os já citados $7,36 \%$. Mas a derrocada não foi geral. O segmento que engloba ficção 
e não ficção (ensaios, reportagens, biografia) subiu $7,65 \%$. O de obras técnicas e científicas aumentou $1,16 \%$. O que despencou mesmo foi a venda de livros religiosos e de autoajuda: 19,18\% (...) Outro número que chama a atenção é o que constata a queda de $11,09 \%$ na venda de didáticos. (Machado, 2013)

Mesmo que não intencionalmente, os contrários aos suportes eletrônicos tendem a unir o fim da Literatura à substituição do livro de papel em seus argumentos; porém, a sobrevivência de ambos parece estar garantida por mais um longo período. Ainda que não se possa fazer prognósticos precisos, as inúmeras iniciativas para preservação, divulgação e compartilhamento de acervos literários online deixam clara a possibilidade de sobrevivência da literatura desvinculada do seu suporte físico em papel. Ademais, a facilidade de acesso e gratuidade de boa parte de obras literárias tem o potencial de democratizar cada vez mais o contato com bens culturais que por razões econômicas, culturais, políticas e sociais impede imensos contingentes populacionais de usufruílos. Portanto, a informatização de bens culturais vem acompanhada de uma imensa oportunidade: a de abrandar desigualdades simbólicas e formar leitores.

Talvez a existência mútua de ambos os formatos - papel e eletrônico seja uma previsão possível sem que se caia no maniqueísmo apocalipse versus redenção que comumente caracteriza as argumentações dos defensores do livro de papel e dos entusiastas das novas tecnologias. De qualquer maneira, a vida da literatura parece estar garantida. Também está cada vez mais garantida a individualização da experiência literária por conta do emaranhado que configura o compartilhamento de informações online. E em um momento histórico tão profícuo para a literatura, a dimensão educativa da Pedagogia da Escolha vem à tona: em meio a tantas oportunidades de escolha, onde se situa o sujeito? Onde se situa a instituição escolar?

\section{A educação murada e o saber canalizado}

Não repetiremos aqui a velha ladainha do fracasso escolar. Negando novamente os maniqueísmos e as totalidades, sabemos das muitas histórias de insucessos escolares, mas também de trajetórias positivas, recompensadas pelo esforço pessoal e pelos mecanismos institucionais. 
Não seria justo, muito menos legítimo, submeter os educadores, teóricos e profissionais da educação apaixonados por sua prática, comprometidos com sua função social, dedicados, fortes, lúcidos, a um discurso totalizante de completo desmerecimento de todos os liames que compõem a instituição escolar. Muito menos justo seria subjugar os heroicos estudantes que, apesar das numerosas e programadas opressões às quais são submetidos ao longo de seu período escolar, dão continuidade à sua trajetória com sabedoria, esforço e criticidade.

Não obstante, é preciso reconduzir a escola a uma função coadjuvante no que concerne à educação contemporânea. Mesmo sua atuação no ensino de dado conhecimento tem hoje sua relevância diminuída, sem que isso signifique que a escola não seja importante ou dela se possa prescindir. A escola é mais um dos espaços nos quais se aprende, uma vez que a convivência nos mais variados espaços da vida familiar, social e cultural não só "ensina" como também educa, no sentido amplo da palavra, isto é, cultiva a convivência. Dessa forma, a escola é mais um espaço, não o espaço educativo; a escola busca dar conta - nem sempre bem, nem sempre mal - da educação funcional, da educação para: para o vestibular, para o mercado de trabalho, para a cidadania, para a inclusão social, para...

No entanto, a educação não pode ser instrumentalizada nem reduzida a cumprir uma função, a educação tem um fim em si mesma, deve cultivar as paixões, os gostos, os conhecimentos e não gerir as estratégias de futuro. O menino apaixonado por dinossauros não está exatamente iniciando seu trajeto rumo a uma carreira de paleontólogo aos nove anos de idade; a menina que quer ser bailarina não se dedica à dança já visando o posto de primeira-bailarina do Teatro Municipal, nem uma bolsa de estudos em uma renomada academia estrangeira. Por que, então, tanto interesse, dedicação, esforço? Pela paixão de fazer, de saber, de experimentar. Porque aqueles conhecimentos suprem sua intrínseca necessidade de conhecimento, de experimentar, de simbolizar, sua "infinita capacidade humana para a associação, para a circulação de experiências e ideias" (Fischer, 1959, p. 13).

Conforme se passa da infância à vida adulta, o conhecimento se reveste, pouco a pouco, de camadas de austeridade, de funcionalidade, o desejo pelo saber é canalizado para o conhecimento "importante" e os interesses que não são validados como tal recebem o nome de hobbies e são, quando são, renegados ao lazer. A entrada no mercado de trabalho, 
grande ritual de passagem para a vida adulta na paisagem urbana contemporânea, trata de encerrar o processo. Somos adultos. Não por acaso, adultos que, frequente e melancolicamente, se pegam contando que "quando eu era criança, adorava desenhar, fazia aula e tudo. Depois a gente vai crescendo, não é?, inglês, escola, vestibular, estágio, nossa!, faz tanto tempo que eu não desenho..."

A escola é reflexo das prioridades e valores da sociedade, cada vez mais investida de mecanismos de controle e avaliação, com o objetivo de selecionar os que ingressarão no ensino superior, os que realizarão labores "qualificados", os não qualificados, os informais... O trabalho é o centro da vida, o que lhe confere valor, e a escola reproduz e prepara para a reprodução dessa situação. Retomando a dicotomia determinismo/ escolha, há um flagrante número de alunos que se dirigem diretamente para o mercado de trabalho após (e durante) a vida escolar por se encontrarem sem outra escolha que não a de "colocar o pão na mesa".

A instituição escolar, portanto, apresenta um recorte dos saberes humanos, o que é importante conhecer para a realização das provas de seleção. $O$ ensino das Ciências Exatas, que abrem menos precedentes para o livre pensamento e para a inexatidão do que as Humanas, se dá através da transmissão de fórmulas e da reprodução de gráficos, esquemas elétricos, estruturas botânicas e composições químicas na lousa, contribuindo fortemente para a não aderência aos conteúdos que explicam a existência humana na Terra, pois nem sempre há laboratórios estruturados ou "tempo" na programação para a experimentação, para o manuseio da matéria, para o devaneio da curiosidade.

Com as Ciências Humanas, a maior possibilidade de interpretações diversas, por vezes antagônicas, exige o estabelecimento de estruturas que garantam os limites do livre pensamento: o ensino de História e Geografia é repleto de fissuras, vazios, omissões e, principalmente, parcialidade; a Língua Portuguesa, ainda que sua abordagem através dos Gêneros Textuais demonstre uma tentativa de maior abrangência de conteúdos e leitura crítica, não raro se reduz a um amontoado de regras gramaticais e estilísticas a serem memorizadas e reproduzidas. Quanto ao ensino de Literatura, a situação é menos complexa. 


\section{Aescolarização daliteratura: o projeto da não- escolha}

Não nos dedicaremos aqui a analisar a formação do cânone literário brasileiro, nem mesmo os critérios estéticos e ideológicos que o compõem, porém, é consenso afirmar que os cânones refletem uma proposição de mundo, valores e ideal de Belo e detêm um caráter projetivo, não se formam sozinhos, naturalmente, mas por meio de um processo de seleção humano, de um processo de escolha visando a nãoescolha, uma escolha mediada. As proposições de mundo, valores e ideal de Belo que o cânone representa, portanto, são proposições, valores e ideais de um grupo de pessoas e toma ares de universalidade através de um processo que, ao contrário, é particular e excludente.

A escolarização da literatura é a transmissão do cânone literário brasileiro aos jovens em formação, é a afirmação de que existe um grupo de obras literárias melhores do que as demais, que devem ser lidas e reconhecidas por todos, depreciando aquelas que não atendem aos critérios estabelecidos para a elaboração da lista sacra. Parte de uma preocupação estética e ideológica, de um projeto de universalização dos ideais de belo, de um cerceamento da oportunidade de escolha:

A preocupação com a função pedagógica do cânone literário toma corpo no século $X X$, no sentido de querer fornecer leituras formadoras ao currículo dos jovens e prepará-los para "reconhecer" as obras de qualidade estética. O paideuma, baseado no gosto pessoal e experiência do crítico enquanto leitor/escritor tem por finalidade, sobretudo, manter a hierarquia na arte e banir da literatura qualquer elemento que contamine a erudição da linguagem e a perfeição da forma (Jacomel, 2008, p. 113)

A transmissão do cânone literário se dá por meio do livro didático que, via de regra, traz o retrato e breve biografia do autor em questão, lista de obras publicadas, condições sócio-históricas de produção, descrição do estilo literário e trechos de suas principais obras. O aluno é orientado a ler a obra para que, ao fim do semestre, seja capaz de responder as questões da prova que, não raro, compreende apenas o conteúdo transmitido pelo livro e pela explicação do professor. Para garantir o direito à livre interpretação, por vezes inclui-se na prova uma questão iniciada por "em 
sua opinião...", mas espera-se uma interpretação que não se distancie das explicações dadas. Pode-se consultar a obra para encontrar um trecho que contenha um exemplo da característica de estilo citada na questão.

Dessa forma, o ensino de literatura bane não só a oportunidade de escolha, o exercício hermenêutico da interpretação, da construção de sentido e da busca de compreensão ao transmitir um projeto estético ideologizante e homogeneizante, como também limita a liberdade de escolha dos educandos frente ao texto, sua comunicação, sua empatia, através da mediação interpretativa e da preocupação única e exclusiva com suas características formais.

Fora da sala de aula, o indivíduo é leitor; dentro, um mero receptor de informações, processo de canalização do saber não muito diverso do que ocorre com o ensino de qualquer outra disciplina; sugerir a um professor de literatura a leitura integral ou de parte da obra em sala de aula torna inviável o cumprimento do programa, com seu foco restrito ao mapeamento histórico das características, autores e obras mais importantes de cada época ou escola literária. Assim, a leitura de literatura se restringe ao tempo fora da escola. Ao omitir praticamente toda a esfera da prática da leitura e da interpretação de textos de ficção dentro da sala de aula, omitese também uma preciosa oportunidade de apaixonar os educandos, de proporcionar experiências estéticas, de discutir perspectivas possível de compreensão de uma obra e, por extensão, da própria realidade. Não por acaso, é fora da escola que seus alunos vão buscar suprir sua intrínseca necessidade de "entrega ao universo fabulado" (Candido, 1995, p. 242). Também não por acaso, os professores de literatura declaram em uníssono que grande parte de seus alunos não gosta de ler ou só lê "porcaria".

\section{Leitura: o projeto da escolha}

Há muitos teóricos que diante da queda das metanarrativas adotaram a estratégia escatológica de decretar a morte de quase tudo o que se desenvolveu no mundo moderno, inclusive a morte da literatura. Almeida e Oliveira (2014) seguem caminho contrário e rebatem os que afirmam que a literatura perdeu sua importância na formação cultural do indivíduo. A literatura sempre foi uma arte de difícil leitura, exercitada por poucos e cujo significado tem mudado ao longo do tempo, como ocorre com todas as práticas culturais. No entanto, se o anseio moderno de universalizar 
a leitura de determinada literatura canônica nunca se realizou, nem por isso essa mesma literatura deixou de ser cultivada, e isso ao lado de uma literatura dita menor, que não tem as mesmas pretensões artísticas ou de leitura de mundo, mas que cumpre seu papel de fornecer fantasia e devaneio aos leitores contemporâneos. Desse modo, renova-se o poder das palavras.

Eu creio no poder das palavras, na força das palavras, creio que fazemos coisas com as palavras e, também, que as palavras fazem coisas conosco. As palavras determinam nosso pensamento porque não pensamos com pensamentos, mas com palavras, não pensamos a partir de uma suposta genialidade ou inteligência, mas a partir de nossas palavras. E pensar não é somente 'raciocinar' ou 'calcular' ou 'argumentar', como nos tem sido ensinado algumas vezes, mas é sobretudo dar sentido ao que somos e ao que nos acontece. E isto, o sentido ou o sem-sentido, é algo que tem a ver com as palavras. $E$, portanto, também tem a ver com as palavras o modo como nos colocamos diante de nós mesmos, diante dos outros e diante do mundo em que vivemos. E o modo como agimos em relação a tudo isso. (Larrosa, 2002, p. 21)

Jorge Larrosa trata de uma experiência comum a todos os homens; é por causa das palavras e através delas que vivemos conosco e com o outro. É através delas que nos relacionamos com o mundo ao nosso redor, pensamos, narramos, debatemos, projetamos, compreendemos.

A literatura, arte do encontro das palavras, compreende a comunicação somada a um caráter estético e a um discurso sensível. Estético por se apresentar enquanto construção estilística; sensível por orquestrar pensamento, sentimento, imaginação na criação literária. Equivocase, no entanto, quem avalia que o processo de criação artística seja fortuito, dependente da inspiração ou de arroubos catárticos. A noção aristotélica de catarse, alívio ou purificação dos sentimentos, encontra mais apoio no público que no artista, trabalhador das formas e das linguagens, da dimensão comunicativa, estética e sensível nos contornos de sua arte. Espera-se, ilusoriamente, que o artista seja a personificação do efeito que sua arte nos causa. Em A Função da Arte, Ernst Fischer nos apresenta um lúcido comentário acerca do fazer artístico: 
Não nos devemos enganar quanto a isso: o trabalho para um artista é um processo altamente consciente e racional, um processo ao fim do qual resulta a obra de arte como realidade dominada, e não - de modo algum - um estado de inspiração embriagante. (...) A paixão que consome o diletante serve ao verdadeiro artista; o artista não é possuído pela besta-fera, mas doma-a. (Fischer, 1959, p. 14) [grifo do autor]

A arte é, portanto, construção, "processo de criação". Comunica uma visão de mundo, um posicionamento, sentimentos particulares que se tornam universais no contato com o público. A comunicabilidade da arte se dá pelo encontro, pelo reconhecimento; o público enxerga pela coincidência ou refutação uma proposição de mundo e a partir daí um diálogo é estabelecido.

Este interesse estético se explica de forma mais simples pelo fato de que o sujeito, enquanto utiliza sua liberdade de tomada de posição perante o objeto estético irreal, é capaz de gozar tanto o objeto, cada vez mais explorado por seu próprio prazer, quanto seu próprio eu, que, nessa atividade, se sente liberado de sua existência cotidiana. Por conseguinte, o prazer estético realiza-se na relação dialética do prazer de si no prazer no outro. (Jauss apud Lima, 2001, p. 76) [grifo do autor]

Defato, o prazer estético se dá através do prazer de si, no reconhecimento de alguma esfera de si na obra alheia; descobrimos algo sobre nós mesmos a cada experiência estética. Em relação à literatura, o leitor se envolve com o texto, ama ou odeia personagens, discorda e os defende, briga, se aflige, se emociona, encontra nas páginas um amigo, habita o mundo proposto durante o tempo da leitura, faz parte dele. É leitor:

Aquilo de que nos lembramos, aquilo que marcou nossas leituras da infância, dizia Proust, afastando-se do moralismo ruskiano, não é o próprio livro, mas o cenário no qual nós o lemos, as impressões que acompanharam nossa leitura. A leitura tem a ver com empatia, projeção, identificação. Ela maltrata obrigatoriamente o livro, adapta-o às preocupações do leitor. (Compagnon, 2006, p. 143)

$O$ ato de ler é também um ato de escolha. Escolhe-se ler, reler, não ler, procurar, guardar, perder-se e achar-se. A leitura não mediada 
promove nos leitores o autodidatismo, a independência, a construção de sua própria trajetória leitora e os posiciona como protagonistas de um processo de aprendizado não escolarizado. Evidentemente, o conhecimento das dimensões formais do texto literário promove uma leitura mais compreensiva, abrangente e profunda, mas estas caminham ao lado, não em oposição à livre interpretação; não sugerimos a substituição de uma pela outra, mas sim o equilíbrio de ambas as esferas.

Por meio da leitura interessada e disposta o leitor se abre para a experiência leitora, para a experiência sensível e estética que percorre o ato de ler. Um leitor formado, ou seja, um leitor interessado, apaixonado pelas palavras, está entregue ao saber desvinculado de funções que, por não visar a um fim, é infinito. Não é a memorização de conceitos, dados e regras que dá sentido à leitura, mas sim a experiência de si, ou como pontua Paul Ricoeur (2008), a compreensão de si mediante a compreensão do texto. A construção da disposição leitora é a pedra angular do exercício da leitura e, consequentemente, do aprendizado de literatura.

Por isso é incapaz de experiência aquele que se põe, ou se opõe, ou se impõe, ou se propõe, mas não se "ex-põe". É incapaz de experiência aquele a quem nada lhe passa, a quem nada the acontece, a quem nada lhe sucede, a quem nada o toca, nada lhe chega, nada o afeta, a quem nada o ameaça, a quem nada ocorre. (Larrosa, 2002, p. 25)

\section{Promessa de vida, promessa de escolha: o século $X X I$, a literatura e a escola}

Não è à toa que a capacidade de escolha do indivíduo, suas alternativas e chances são exaltadas sobremaneira no mundo contemporâneo; de fato, estamos inseridos em uma dimensão espaço-temporal que permite um jogo identitário e um desprendimento cultural imenso, o que contribui para o constante repensar de caminhos. Nada parece nos prender, tudo é possível. Neste cenário, a única certeza é a de que fazer, desfazer e refazer escolhas não só é possível como também necessário. Constantemente nos deparamos com caminhos, possibilidades que potencialmente preencherão nossas atuais necessidades para que, em pouco tempo, tenhamos criado novas outras e, ciclicamente, busquemos alternativas que nos retirem do sedentarismo atual. Nomadismo 
identitário (Maffesoli, 2001). E em um mundo permeado de escolhas, não somos estimulados a escolher, a protagonizar nossos próprios destinos e trajetórias educativas.

Salvo experiências escolares "alternativas", a instituição escolar brasileira não aposta na capacidade de escolha e de autogestão do sujeito; pelo contrário, desconfia dela e está organizada para atender às exigências curriculares de exames vestibulares e do mundo do trabalho. Não há tempo para escolhas, não há tempo para sujeitos, não há tempo para discussões e para a compreensão, apenas para cumprir o planejamento.

Não é de hoje que se discute o obsoletismo do modelo escolar, condição que só se agrava com a entrada da internet no cotidiano de um número cada dia maior de estudantes. E o que é a disponibilidade gratuita de um sem número de conteúdos se não um constante exercício de escolha? Escolhe-se ler este ou aquele artigo, clicar no hiperlink, ler o texto relacionado, "curtir", "compartilhar", "favoritar", pesquisar, descobrir, conhecer. A internet favorece a individualização da trajetória educativa, a particularização do conhecimento, se adapta às necessidades do sujeito, funciona como o rizoma de Deleuze e Guattari (2011), ideia de sistema aberto que desobriga o conhecimento de um conjunto inicial de princípios. Pode-se chegar ao conhecimento por caminhos distintos.

No caso da literatura, como dito acima, a internet vem cooperando fortemente para sua preservação e circulação: acervos riquíssimos estão disponíveis para consulta e download, campanhas e iniciativas de promoção da leitura são criadas, autores são divulgados, textos e mais textos são compartilhados legal e ilegalmente. Constante exercício da escolha e da autogestão da trajetória formativa. Nenhuma novidade para os leitores apaixonados, um mundo a ser descoberto pelos não leitores.

Quando dissemos, no início do artigo, que é para aqueles que ainda se encontram à margem do modus operandi e das teorizações a respeito da contemporaneidade que os olhos dos teóricos, dispostos e educadores devem se voltar neste século, nos referíamos, também, à plena oportunidade de uso das ferramentas de promoção do conhecimento surgidas nos últimos anos; e por "plena", nos referimos à escolha, à assimilação desta pelo sujeito individual, não à imposição cega de tecnologias que, revestidas de novidade (e benfeitoria), escondem o discurso sectarista, excludente e homogeneizador que é de conhecimento de todos. Desnecessário dizer que o "não" também é uma escolha. 
A internet é uma formadora de leitores em potencial não apenas através dos textos escritos para ela, mas principalmente por aqueles que circulam por meio dela. Mostrar ao aluno este mundo infinito de possibilidades é guiá-lo para uma possibilidade nova de formação, menos linear e programada e mais aberta ao fortuito, ao acaso, ao plural. A escolarização do conteúdo literário peca ao localizar abaixo dos aspectos formais a leitura em si, a leitura que encanta, que forma leitores, velha conhecida dos já leitores, novidade para os leitores em formação. É isso que Todorov (2010) critica em Literatura em Perigo, o excesso de estudos formais não pode prescindir do prazer da leitura, prazer de descobrir ou inventar sentidos, seja para o mundo, para as relações cotidianas, para o outro e para si mesmo.

Em tempos de "também", não de "isto ou aquilo", é urgente recuperar a amplidão; no caso do ensino de literatura, abandonar discursos de castas faz-se necessário para a real formação leitora, que não se encerra no Ensino Fundamental; pelo contrário, passa pelo Ensino Médio e dura enquanto estamos vivos. Formar leitores disponíveis, abertos, sagazes e curiosos para que possam navegar pela infinidade de conteúdos que, pela primeira vez na história, estão disponíveis para, se não em sua totalidade, grande parte da população. Garantir àqueles que, por motivos diversos, estão aquém das práticas "pós-modernas", o conhecimento e a possibilidade de uso real das ferramentas e suportes. Criar as bases para o exercício da escolha e suas implicações - a ponderação, a pesquisa, a criticidade. Acreditar no sujeito, acreditar em sua capacidade de fazer escolhas.

\section{Referencias bibliográficas}

Almeida, Rogério de (2010). Educação Contemporânea: a sociedade autolimpante, o sujeito obsoleto e a aposta na escolha. Revista Educação: Teoria e Prática, v. 20 (34):4764.

Almeida, Rogério de e Oliveira, Louis José Pacheco de (2014). A tão difícil arte de ler ou do mundo como texto. Polifonia, v. 21 (30): 269-288.

Candido, Antonio (1995). "O Direito à Literatura". Vários Escritos. São Paulo: Duas Cidades. 
Compagnon, Antoine (2006). "O Leitor". O Demônio da Teoria - Literatura e Senso Comum. Belo Horizonte: Editora UFMG.

Deleuze, Gilles e Guattari, Félix (2011). Mil platôs. Vol. 2. São Paulo: Editora 34.

Ferreira-Santos, Marcos e Almeida, Rogério (2012). Aproximações ao imaginário: bússola de investigação poética. São Paulo: Képos.

Fisher, Ernst (1959). "A Função da Arte". A Necessidade da Arte. São Paulo: Círculo do Livro.

Jacomel, Mirele Carolina Werneque (2008). Relações de Poder e a Literatura Brasileira. Revista Grifos, 25: 109-121 Disponível em: http://apps.unochapeco.edu.br/revistas/ index.php/grifos/article/viewFile/658/421. Acesso em: 13 Ago. 2013.

Jauss, Hans Robert (2001). "O Prazer Estético e as Experiências Fundamentais da Poiesis, Aisthesis e Katharsis". In LIMA, L.C. A Literatura e O Leitor - Textos de Estética da Recepção. 2 ed. São Paulo: Paz e Terra.

Larrosa, Jorge. Notas sobre a experiência e o saber da experiência. Revista Brasileira de Educação, 19: 20-28.

Lipovetsky, Gilles (1989). A Era do Vazio. Lisboa: Relógio D’Água.

Lyotard, Jean-François (1993). O pós-moderno. Tradução: Ricardo Correia Barbosa. 4. ed. Rio de Janeiro: José Olympio.

Machado, Ana Maria (2013). "Comida para o pensamento". Folha de São Paulo, São Paulo, 8 Ago. 2013. Disponível em: http://www1.folha.uol.com.br/opiniao/2013/08/1323256ana-maria-machado-comida-para-o-pensamento.shtml. Acesso em: 12 Ago. 2013.

Maffesoli, Michel (2001). Sobre o nomadismo: vagabundagens pós-modernas. Rio de Janeiro, Record.

Morin, Edgar (2008). Ciência com Consciência. Rio de Janeiro: Bertrand Brasil, 1999.

Ricoeur, Paul (2008). Interpretação e ideologias. Rio de Janeiro: Francisco Alves, 2008.

ShowMeTech (2013). Metade da população mundial terá acesso à internet até 2017. ShowMeTech, São Paulo, 7 Jun. 2013. Disponível em: http://showmetech.band.uol.com. br/metade-da-populacao-mundial-tera-acesso-a-internet-ate-2017/. Acesso em: 8 Jun. 2013.

Todorov, Tzvetan (2010). A literatura em perigo. Rio de Janeiro: Difel. 